\title{
Comentário: A AÇÁo No TEMPO: REFLEXo dA MULTIPLICIDADE
}

\author{
Maria Cristina Mariante Guarnieri ${ }^{1}$
}

Referência do texto comentado: PERIUS, Oneide. A multiplicidade originária: uma leitura da filosofia de Franz Rosenzweig. Trans/Form/Açáo: revista de filosofia da Unesp, vol. 43, n. 4, p. 255-270, 2020.

O que está em questão é a percepção de que a obra desse filósofo judeu do início do século $X X$, tão pouco frequentada entre nós, se impóe como uma forma extremamente lúcida e desafiadora de nos fazer perceber a importância e a centralidade de certas questóes, as quais, em plena aurora do século XXI, ainda não foram colocadas na ordem do dia.

Oneide Perius

Nos termos de sua profundidade, sua originalidade, seu imenso conhecimento, o poder de sua mente, e a compaixão de sua visão (sem mencionar sua grande influência nos pensadores não judeus tanto quanto nos pensadores judeus),

Franz Rosenzweig figura, juntamente com Martin Buber e Emmanuel Levinas, como um dos mais importantes pensadores judeus do século $X X$.

Hilary Putnam

Comentar um texto sobre Franz Rosenzweig é ter a oportunidade de ampliar o debate sobre um autor com um consistente trabalho intelectual,

${ }_{1}$ Psicóloga clínica; Doutora em Ciências da Religião, PUC-SP; Docente do Instituto Junguiano de Ensino e Pesquisa (IJEP); Pesquisadora e coordenadora do Grupo de Judaísmo Contemporâneo do Laboratório de Política, Comportamento e Mídia da Fundação São Paulo/ PUC-SP. São Paulo, SP, Brasil - LABÔ; crisguarnieri@uol.com.br

(iD) https://orcid.org/0000-0003-3144-2269

http://dx.doi.org/10.1590/0101-3173.2020.v43n4.17.p277

This is an open-access article distributed under the terms of the Creative Commons Attribution License. 
construído em uma vida curta (1886-1929), mas muito produtiva. O reconhecimento de Perius, em seu texto, do judaísmo de Franz Rosenzweig, guiará meu comentário. Primeiro, pelo fato de o próprio Rosenzweig ter admitido que permaneceria judeu, após a experiência na sinagoga em Berlim, em 1913, recusando assim a conversão ao cristianismo e todo o processo de assimilação, devido ao contínuo crescimento do antissemitismo, nos meios universitários alemães. Permanecer judeu, para Rosenzweig, pedia outro modo de pensar, uma nova forma de conceber a realidade, que, reconhece ele próprio, pode ser encontrada em sua própria tradição.

Outro ponto que queremos acrescentar a este comentário é a implicação da ação no ethos judaico. Por reconhecer que, em seu "novo pensamento", o conhecimento ocorre no tempo, o conhecimento está atado àquele exato instante, portanto, o ato é um ato no presente. Como o agir está intimamente ligado à tradição judaica, pois é a ação que importa, retomamos aqui a importância do método judaico de pensar, onde o fundamental é perceber a importância da linguagem, em uma realidade constantemente mutável; o nome, a palavra, a linguagem tornam-se o elemento permanente que serve de ponte entre Deus, ser humano e mundo. O significado de uma palavra é aquele que melhor se desdobra em ação no mundo. Para Rosenzweig, como judeu, estar implicado no ato está relacionado com a sua responsabilidade com a vida e com o que ele irá fazer com ela, diante de Deus.

A morte entra nessa reflexão como constatação de que todo mortal vive a angústia da morte, e que grande parte da filosofia se constrói a partir da negação das angústias do terreno, uma tentação que será inevitavelmente vencida pela própria experiência concreta, a qual inviabiliza a racionalização da morte em um sistema de pensamento. A morte não pode ser abstraída sobre o risco do sofrimento do indivíduo e, portanto, sobre o risco, como frisa Perius, de uma lógica da totalidade levar, no limite, à aniquilação do outro. Essas são questóes fundamentais a que a filosofia, hoje, não pode se furtar.

Segundo Leora Batnitzky (2011, p. 81-82), a questão, para Rosenzweig, era se o judeu moderno poderia retornar à experiência do viver de acordo com sua tradição. Seu judaísmo é fundado com base na experiência pessoal. Essa experiência tem como ponto determinante o Yom Kippur de 1913, em que o autor, em diálogo, afirma que experimentou a presença de Deus e observa que a linguagem judaica é parte de sua memória, é a forma de expressão dessa experiência. Na realidade, podemos observar, através de sua obra, que pode haver uma relação cooperativa entre filosofia e religiấo. Entendemos que, nesse 
sentido, a proposta de Rosenzweig é manter o embate como necessário ao conhecimento.

Rosenzweig critica a filosofia tradicional e sua busca por uma "essência" das coisas. A filosofia suprime o singular e isolado e, por isso, ela é idealista. O desdobramento dessa crítica leva o autor a apresentar seu "novo pensamento", cujo ponto de partida é a Revelação, a categoria fundamental, mas entendendo que o conceito de Deus não é mais acessível do que o conceito de homem ou de mundo: deles sabemos pouco, ou seja, tudo e nada. Para Rosenzweig, tudo isso é passível de ser experimentado, a partir do que poderíamos chamar de presentidade, isto é, não podemos descrever a criação-revelação-redenção como um processo já acontecido, visto como algo externo e objetivo, porém, em vista de uma experiência vivida como ocorrência histórico-existencial que nos afeta no presente (GUARNIERI, 2011).

Iniciando sua reflexão com a questão da morte, Rosenzweig levanta, com base no horror que experimentamos diante da nossa condição finita, uma espécie de negação, por parte da filosofia. Essa, ao estabelecer complexos sistemas de pensamento, tenta racionalizar uma experiência que acaba resistindo a essa mesma racionalização, por ser a morte algo inexorável e insuprimível. A morte, quando reduzida a um conceito, não consegue anular nem a intensidade, nem a solidão de sua experiência: "O homem não deve retirar de si a angústia do terreno: no medo da morte deve permanecer." (ROSENZWEIG, 1997, p. 44).

Em face da contingência do mundo, o pensamento, estimulado pela angústia do pensador, busca a neutralização. Nada melhor que um conceito sobre o real, para nos afastar desse mesmo real, para nos afastar do acaso, do real, do trágico, do múltiplo. Entre o ser e o pensar, entre a existência e a essência, há de se encontrar uma identificação, como também uma não identificação. O pensamento referido ao ser também é, dado que é referido a si mesmo, uma multiplicidade. Isso significa dizer que a tensão expressa pela alteridade absoluta da morte tende a ser reduzida, no conceito do sistema filosófico, a uma situaçáo de neutralidade: o a-racional da morte não deve perturbar a racionalidade do Todo (GUARNIERI, 2011).

Diante do nada, duas vias se apresentam: a do sim e a do não. Deus é ato, e o ato rompe o nada. É a criação, o sim, a ação que se abre na perspectiva do acontecer. Quando perguntarmos pela essência, pelo o que é, nós nos perguntamos pela origem; quando perguntamos pelo ato, buscamos por 
seu princípio e aí se abre a possibilidade. O sim é o princípio, um algo que se tornou fugitivo do nada, através da própria liberdade: é o ato. $\mathrm{O}$ nada, então, não é determinado: é fonte de determinação, o ponto de partida do pensamento sobre Deus, é o lugar do estabelecimento do problema. Dessa forma, a multiplicidade "[...] é a inscrição de uma abertura fundamental e de uma potência diferidora na própria realidade de cada um desses elementos" (PERIUS), é a experiência concreta de onde emerge o pensar, o agir, a linguagem, que se revela no "e" e nele se reafirma.

Nesse ponto, podemos observar a contribuição do "método judaico de pensar” de Rosenzweig. Os elementos se correlacionam, contudo, eles só são nessa correlação. A experiência, para o autor, significa um pensamento contaminado pela temporalidade. $\mathrm{O}$ conhecimento está atado àquele exato instante: como destacamos acima, um ato é um ato no presente. $\mathrm{O}$ novo pensamento em estreita ligação com o agir, pensa em diálogo; o falar está ligado ao tempo e requer que o outro - concretamente - escute e se manifeste, sem que se saiba qual será o pensamento construído pelo outro. É nessa tensão que se entende que o pensamento deve fluir, sem que se saiba onde irá parar. "Náo sei de antemáo o que o outro me dirá, porque nem mesmo sei o que eu vou dizer.” (ROSENZWEIG, 2000, p. 126). É um modo de pensar que recebe influência da tradição talmúdica e que, de certa forma, pode ser encontrado também no que entendemos hoje como epistemologia da controvérsia.

$\mathrm{O}$ velho e o novo pensar são apontados por Rosenzweig como um pensar "lógico" e "gramatical", respectivamente. No caso do gramatical, o indivíduo deve levar o tempo a sério, pois "falar significa falar para alguém e pensar para alguém; e este alguém é sempre bem definido e tem não só ouvidos como todos, mas também uma boca" (ROSENZWEIG, 2000, p. 127). Conforme o autor, é na conversação real que algo acontece. E assim também será seu método de traduzir, reforçando que, ao se traduzir, deve ocorrer um estranhamento; um modo de apresentar o estrangeiro, como ele é, para que eu possa ouvi-lo. A tradução ocorre de nação para a nação, de civilização para civilização e de religião para religião e, principalmente, na mesma língua: ao falar, o outro que recebe traduz. Toda fala, para Rosenzweig, é tradução.

Segundo o filósofo de Kassel, um idealismo ou anteidealismo teriam o mesmo perigo: a tentaçáo dos conceitos, que objetivam o ser no real e, ao mesmo tempo, acabam retirando-o fora do fluxo da vida. Paradoxalmente, nossos "ismos", marca de um pensamento abstrato, possibilitam um sentido 
ao agir, mas o retiram do tempo. Há um agir em cada instante, o qual flui em um movimento contínuo do próprio viver. A única coisa que temos de permanente é o nome. Nome não é a essência das coisas, das pessoas ou das vivências, entretanto, para o senso comum, é ele quem possibilita uma certa estabilidade. $\mathrm{O}$ nome se confunde com o conceito universal, justamente porque nos esquecemos do privilégio humano de nomear (ROSENZWEIG, 1992) A linguagem, para Rosenzweig, terá importância fundamental. A linguagem, que é transmitida e garantida pela tradição, é uma ponte entre o mundo e as coisas. O significado de uma palavra é aquele que melhor se desdobra em ação no mundo; uma ação que é uma experiência de significados, isto é, uma ação que é transformadora e produz resultados, que, ao se estabilizar, aponta a sua consistência como algo eficaz no tempo.

O conhecimento em Rosenzweig se dá nessa tensão entre a multiplicidade de sentidos e significados, que está sob o risco constante de reducionismo, e a dissipação contínua, imposta pela relativização do processo de conhecimento e pela presença de um sentido histórico. Essa tensão não pode ser excluída, e o que caracteriza sua presença é justamente a temporalidade. E é na alteridade da existência, na tensão entre vida e morte, que se torna possível sair da paralisia do pensamento. O conhecimento epistêmico, conforme Rosenzweig, se dá no diálogo, no embate, no conflito de conceitos e ideias, que, em sua controvérsia, constitui um epistemologia própria. E aqui, portanto, um desafio se abre à filosofia, que é indagada pela própria vida, pois é no encontro com a morte que nos é revelado o caráter insuficiente da linguagem, pois ele nos serve apenas de instrumento de relaçáo com o mundo. A vida continua em seu fluxo e, nessa relação, é possível que o agir entre em contato com o real e balize o pensar. Há uma tensão que se estabelece entre o ser e o pensar, uma tensão que tem como fundamento a angústia ontológica, cuja inquietude não permite descanso, na busca de conhecimento (GUARNIERI, 2011).

O novo pensamento exige, como escreve Perius (2020, p. Xxx) que se leve "[...] a sério a exigência ética de renovar o pensamento, quando a própria realidade o exige." Nesse sentido, o convite para ler Rosenzweig que Perius promove, com seu texto, é fundamental para as nossas questóes éticas e políticas contemporâneas, um desafio à filosofia, lançado pela própria constataçáo de que a vida deve ser compreendida no tempo, como um evento, isto é, com a certeza de que estar diante de Deus é estar sem tranquilidade e sem autonomia, é estar em uma desconfortável tensão, a qual caracteriza a 
experiência concreta de estar vivo - e esse "desconforto" se dá em virtude de o filósofo ser confrontado com questóes existenciais.

Essas questôes não nos abandonam, porque sabemos mais sobre as coisas, sobre o mundo que nos rodeia, ou porque conquistamos maior autonomia e achamos que sabemos muito. $\mathrm{O}$ conhecimento apenas nos ajuda a criar uma ilusão mais sofisticada para o nosso cotidiano. A leitura de Rosenzweig tornase necessária, a fim de contemplar o encontro entre a filosofia e o judaísmo, um confronto sustentado na tensão entre Jerusalém e Atenas (cf. STRAUSS, 1992). Essa relação não só está nas raízes do pensamento ocidental, como pode ser um fonte importante para estabelecer uma crítica sobre os valores do homem moderno.

\section{REFERÊNCIAS}

BATNITZKY, Leora. How judaism became a religion: an introduction to Modern Jewish Thought. USA: Princeton University Press, 2011.

GUARNIERI, Maria Cristina Mariante. Angústia e Conhecimento: uma reflexão a partir dos pensadores religiosos Franz Rosenzweig, Sören Kierkegaard e Qohelet. São Paulo: Editora Reflexão, 2011.

ROSENZWEIG, Franz. Das Büchlein vom gesuden und kraken Menschenverstands. Frankfurt am Main: Jüdischer Verlag im Surkhamp Verlag, 1992.

ROSENZWEIG, Franz. La Estrella de la Redención. Salamanca: Ediciones Síguem, 1997.

ROSENZWEIG, Franz. The New Thinking. In: Philosophical and Theological Writings. Trad., edição, comentários e notas de Paul W. Franks e Michael L. Morgan. Indianapolis: Hackett Publishing Company, Inc., 2000.

STRAUSS, Leo. Jerusalem e Athenas. In: Jewish Philosophy and the crisis of Modernity. Albany: State University of New York Press, 1992.

Recebido: $21 / 10 / 2020$

Aceito: 26/10/2020 